\title{
O LÓCUS DA SENSIBILIDADE NO FENÔMENO ÉTICO: REFLEXÕES A PARTIR DE KANT E LEVINAS
}

\author{
G.S. SANTOS ${ }^{1 *}$ e E. D. SILVA ${ }^{2}$ \\ ${ }^{1}$ Instituto Federal de São Paulo - IFSP \\ ${ }^{2}$ Secretaria de Estado de Educação do Estado de São Paulo \\ genivaldo@ifsp.edu.br ${ }^{*}$
}

Artigo submetido em novembro/2014 e aceito em julho/2016

DOI: $10.15628 /$ holos.2016.2578

\section{RESUMO}

O presente artigo é fruto das reflexões e pesquisas realizadas no GEPEES - Grupo de Pesquisa Ética, Educação e Sociedade, desenvolvidas na UNESP (Campi Assis e Marília). Por meio de estudo exploratório, pretende-se problematizar duas vozes contrastantes em relação ao lócus da sensibilidade no fenômeno ético, não para compará-las, mas para destacar o contraste e metodologicamente sustentarmos uma friç̧ão de suas propostas para mantermos as diferenças. Para este trabalho, não nos interessa os resultados em termos de saber se Kant é mais verdadeiro do que Levinas ou viceversa, mas alimentarmos um debate que visa resgatar e problematizar o elemento da sensibilidade (tais como o corpo, as paixões, os afetos) na tradição filosófica em geral e no discurso ético, em particular. Se para Kant a ação ética prescinde da sensibilidade. Para Levinas, a ação ética ocorre no encontro sensível com a alteridade, através da fruição, da aproximação e da vulnerabilidade.

PALAVRAS-CHAVE: Sensibilidade, Ética, Kant, Levinas, Educação

\section{THE LOCUS SENSITIVITY IN ETHICAL PHENOMENON: REFLECTIONS FROM KANT AND LEVINAS}

\begin{abstract}
This article is the result of reflection and research conducted in GEPEES - Ethics Group Research, Education and Society, developed at UNESP (Campi Assis and Marilia). Through an exploratory study, we intend to discuss two contrasting voices in relation to locus of ethical sensitivity phenomenon, not to compare them, but to highlight the contrast and methodologically sustain friction of his proposals to keep the differences. For this work, not interested in the results in terms of
\end{abstract}

whether Kant is truer than Levinas or vice versa, but we feed a debate that aims to rescue and discuss the sensitivity of the element (such as the body, the passions, the affections ) in the philosophical tradition in general and the ethical discourse in particular. If Kant ethical action waives the sensitivity. For Levinas, the ethical action occurs in sensitive encounter with otherness, through enjoyment, approximation and vulnerability.

KEYWORDS: Sensitivity, Ethics, Kant, Levinas, Education 


\section{INTRODUÇÃO}

O presente artigo é fruto das reflexões e pesquisas realizadas no GEPEES - Grupo de Pesquisa Ética, Educação e Sociedade, desenvolvidas na UNESP, cujo foco de estudo circunscrevese na reflexão da importância da sensibilidade na ação ética, especialmente no campo educativo. Para tanto elegemos dois autores da tradição filosófica que assumem perspectivas distintas e até mesmo inconciliáveis, o que pode nos transportar para uma dimensão aporética, essencialmente filosófica.

Refletindo sobre a razão e a paixão do fenômeno ético, Carvalho (2012) reconhece o caráter polêmico que tais vocábulos encerram no debate filosófico desde Platão. Nas filosofias de base platônica, segundo Carvalho, "O mundo no interior da caverna, que é o mundo sensível e pleno de paixões, é fonte de conhecimentos falsos, fortuitos e acidentais" (CARVALHO, 2012, p. 200). Nesta perspectiva, a vida ética dependeria do conhecimento, do intelecto, pois "quem conhece bem, age bem", muito embora Aristóteles, na Grécia Clássica, segundo Gadamer (1996) ${ }^{1}$, já tenha buscado um equilíbrio para a questão do conhecimento no fenômeno ético.

Seguindo Carvalho (2012), a desconsideração pelo mundo dos desejos, das paixões ecoou na filosofia contemporânea, exemplificado com a postura dos filósofos da Escola de Frankfurt, especificamente em Horkheimer e Adorno, ao proporem uma história subterrânea do corpo. Para Carvalho (2012), o "[...] corpo, como morada das paixões, teria sido condenado como depósito absoluto do mal em contraposição ao espírito, ao mundo intelectual, reverenciados como suprassumo do bem, [...]" (CARVALHO, 2012, p. 200), justificando assim, no processo civilizatório, o domínio da natureza e das paixões pelas diretrizes racionais.

No bojo desta questão, propomo-nos interpelar os sentidos da sensibilidade no fenômeno ético a partir da reflexão de dois autores da tradição filosófica, Immanuel kant e Emanuel Levinas. A escolha destes autores tem o sentido de marcar um contraste acentuado nestas duas possibilidades de respostas. Pois se para Kant, a sensibilidade, pensada pelo autor como paixão, é um vício e uma doença (LOPES, 2013) que deve ser curada pela Razão², para Levinas (1980), tratase de um traço essencial do homem e da ética, estabelecido antes mesmo da constituição da Razão e precedendo-a.

\footnotetext{
${ }^{1}$ A questão levantada por Aristóteles diz respeito a possibilidade de um conhecimento filosófico do homem como ser ético, bem como a investigação acerca da função do saber na constituição do comportamento ético. Questão que implica uma retomada de alguns pressupostos aristotélicos, o primeiro deles, diz respeito à exatidão/precisão do conhecimento intelectual, isto é da episteme. Desse modo, quando Aristóteles refere-se a um conhecimento filosófico do homem como ser ético, diz respeito a um "objeto" histórico e mutável. A episteme, de acordo com a tradição aristotélica, refere-se sempre ao conhecimento do invariável que possibilita descobrir leis que governam a Physis. A questão de fundo se configura do seguinte modo: o conhecimento científico (episteme) do invariável tem condições de produzir conhecimento sobre o fenômeno ético, sempre variável e mutável em seus preceitos? A concretude da situação é determinante para que ação ética se efetive, neste sentido, o papel do conhecimento no comportamento ético deve se adequar à situação concreta, para que, devido sua generalidade não perder de visto o sentido ético da situação, devendo portanto restringir-se ao que tange a seu poder de exatidão e precisão, auxiliando como "traçado geral dos seus contornos [como] um tipo de apoio à consciência ética" (GADAMER, 1996, p. 49).

${ }^{2}$ Retomando o pensamento kantiano, especialmente dedicado a formação moral, Renata Andrade Lopes em sua tese de doutorado nos leva à fórmula encontrada pelo autor para tratar das paixões (sensibilidade) quando o assunto é moralidade, reproduzindo o trecho de Kant selecionado pela autora: "[...] Se a afecção é uma embriaguez, a paixão é uma doença que tem aversão a todo e qualquer medicamento" (KANT, 2009, p. 163 apud ANDRADE, 2013, p. 81)
} 
Pretendemos com esta brevíssima introdução, problematizar duas vozes contrastantes em relação ao lócus da sensibilidade no fenômeno ético, não para compará-las, pois assim não seríamos justos com os autores e seus respectivos horizontes de sentido histórico, mas para manter o contraste e metodologicamente sustentarmos uma friç̧ão de suas propostas para mantermos as diferenças. Para este trabalho, não nos interessa os resultados em termos de saber se Kant é mais verdadeiro do que Levinas ou vice-versa, mas alimentarmos um debate que visa resgatar e problematizar os elementos da sensibilidade (tais como o corpo, as paixões, os afetos) na tradição filosófica em geral e no discurso ético, em particular.

\section{KANT: O HOMEM CORTADO EM DOIS.}

Kant dedicou sua vida para investigar os meios pelos quais a Natureza dotou a humanidade para alcançar o seu destino, a saber, a cultura. A cultura é o meio pelo qual são desenvolvidas as disposições naturais do homem e colocadas a serviço da civilização. Contudo, conforme especifica Edmilson Menezes no Apêndice à tradução de Começo conjectural da história humana (2010, p. 26), "Quando se trata de designar o último fim da humanidade, não é a civilização (Zivilissierung), mas a cultura (Kultur) que é privilegiada". A civilização é o desdobramento do desenvolvimento e a representação de uma cultura, a da prudência, que permite que o homem se adapte à sociedade, seja nela reconhecido, amado e tenha influência. É preciso, portanto, que o homem tenha compreensão dos limites e das possibilidades de seu conhecimento, no campo das ciências e da epistemologia, como também adquira uma consciência moral para que seja capaz de conduzir sua vida de modo ético, de acordo com a boa vontade.

Foi tendo em vista o problema ético da fundamentação da moral que o filósofo de Konisberg empreendeu constituir não um novo sistema ético, mas estabelecer, conforme observa Martha S. Mateo (1981), uma fórmula que permita aos princípios morais diversos comparecer perante a vontade humana e adquirir um autêntico valor moral. (MATEO, 1981, p. 11). Foi por desconfiar da determinação imediata da vontade, que pelo querer, ao aderir a um conteúdo pode ser dirigida pelos sentimentos, as emoções e as inclinações, que Kant buscou ir da moral à moralidade, à formalidade da lei, feito representado de modo emblemático na Fundamentação Metafísica dos Costumes. Mateo observa que a formalidade da lei moral se dá porque ela relaciona todos os princípios morais possíveis e rege a relação dos mesmos com a vontade, donde a autora chamar de um metaprincípio moral. Deste modo, a razão não é a fonte dos princípios da moral, ela é "el último tribunal ante El cual comparecen todos lós princípios prácticos para tomar la forma adecuada de determinación de la voluntad" ${ }^{3}$. (MATEO, 1981, p. 12). Assim ocorre quando a máxima "Ama a Deus sobre todas as coisas e a teu próximo como a si mesmo" é submetida ao crivo da razão. Kant exclui o amor como sentimento para torná-lo um dever determinado pela boa vontade. O mesmo ocorre quando alguém sente compaixão de um desabrigado e busca ajudá-lo, este sentimento é o elemento originário da ação ao qual o conteúdo da vontade se conforma. Esta ação, porém, não possui valor moral, pois, está ligada a honra e a felicidade, a não ser que a vontade se purifique do sentimento e adote o princípio "ajudar o próximo" como um dever ${ }^{4}$. Assim,

3 "o último tribunal ante o qual comparecem todos os princípios práticos para tomar a forma adequada de determinação da vontada". (Tradução livre)

$4 \quad$ Kant argumenta que o ser humano não pode nunca ser tratado como meio, mas, sempre como um fim em si mesmo, "age de tal maneira que uses a humanidade, tanto na tua pessoa como na pessoa do outro, sempre simultaneamente como fim e nunca como meio" (KANT, 1974, p. 229). 
uma boa vontade seria o princípio da ação; o sentimento poderia até coincidir com esta, mas, não teria primazia, apareceria apenas secundariamente.

Mateo aponta para aquele que pode ser um ponto fraco do sistema ético kantiano, a universalização do homem de seu tempo, egoísta, ávido pelas riquezas e pelo luxo. Menezes comenta que para Kant, tal como em Rousseau, a vida em conjunto leva ao surgimento de novos impulsos e que é notável no filósofo de Konisberg a preocupação com sua época por conta do aumento do supérfluo, das paixões despertadas pela comparação e da tirania. (KANT, 2010, p. 115). De fato, ao falar do surgimento da razão, o filósofo identifica o mau já na raiz da questão ética humana: "A história da natureza começa, por conseguinte, pelo bem, pois ela é obra de Deus; história da liberdade começa pelo mal, porque ela é obra do homem. No que concerne ao indivíduo, que, no uso de sua liberdade não pensa senão em si, essa mudança foi uma perda; para a natureza, cujo fim, em se tratando do homem, visa somente à espécie, foi um ganho. (KANT, 2010, p. 25). Deste modo, Kant depreciou a dimensão sensível do homem, caracterizou o egoísmo como um sentimento dominante que direciona a vontade para valores tais como a honra, a fortuna e o poder. A razão também pode cumprir um papel nefasto, pois, frequentemente exalta os desejos originais e aumenta a voluptuosidade.

O homem pode, contudo, desvencilhar-se de sua condição de menoridade e heteronomia, chegar à consciência de si e ao estatuto de pessoa moral. Nesta busca pela compreensão de si o homem se descobre dotado pela Natureza de razão e sensibilidade ${ }^{5}$, porém, dividido, cortado, em duas dimensões heterogêneas, conforme salienta Mateo (1981, p. 21): 1) como ser racional, realidade pura; 2 ) como ser psíquico-biológico, como realidade empírica. O homem é livre apenas pela causalidade livre pertencente ao inteligível, pois, está submetido à lei ditada exclusivamente pela sua razão. O mesmo não ocorre quando se guia por sua sensibilidade, pois está submetido a leis de uma causalidade natural. De outro modo, também a finalidade destas duas dimensões são distintas. Segundo Mateo (1981, p.23) a razão é em última instância a finalidade da história. Já a dimensão da sensibilidade tem como finalidade a felicidade que é alcançada através da satisfação do instinto e do desejo. Aqui, a autora alerta: "La razón no puede tener como finalidad el meditar sobre los medios para conseguir la felicidad, porque entonces aparecería en el hombre como un instrumento gratuito, superfluo, que realiza la misma finalidad que el instinto. Ela se aparta radicalmente de la dimensión sensible para cumplir su fin: guiar la voluntad, producir una buena voluntad". ${ }^{6}$ (MATEO, 1981, p. 23). Por isso, "la buena voluntad, en muchas ocasiones, debe anular a la felicid. La felicidad se posterga para que la virtud aparezca". ${ }^{7}$ (MATEO, 1981, p.28). A vontade recebe as intenções para a ação e se conforma a elas de acordo com a sensibilidade ou de acordo com a razão.

Na Crítica da Razão Pura acerca da razão e da felicidade Kant afirma: "Para nossa razão a felicidade, por si só, está longe de ser o bem completo. A razão não a aprova (por mais que a inclinação o quisesse, quando ela não está ligada à dignidade de ser feliz, isto é, ao bom

\footnotetext{
${ }^{5} \mathrm{O}$ conceito kantiano de sensibilidade compreende as forças instintivas, o sentimento relacionado com as afecções sensíveis e todos os sentimentos, sendo patológica, segundo o seu caráter de passividade.

6 "A razão não pode ter como finalidade meditar sobre os meios para conseguir a felicidade, porque então apareceria no homem como um instrumento gratuito, superfluo, que realiza a mesma finalidade que o instinto. Ela se aparta radicalmente da dimensão sensível para cumprir seu fim: guiar a vontade, produzir uma boa vontade". (Tradução livre) 7 "A boa vontade, em muitas ocasiões, deve anular a felicidade. A felicidade se posterga para que virtude apareça". (Tradução livre)
} 
comportamento da moral". (KANT, 2012, p. 589). Ou seja, a união entre o merecimento de ser feliz, a moralidade, a virtude e a felicidade constituem o sumo-bem. Contudo, esta união pode não ocorrer e a ação ética aparecer desvinculada da felicidade. O sujeito pode agir moralmente e ser infeliz, ao passo que outros podem estar agindo imoralmente e gozando da fruição e do benefício da felicidade. Deste modo, a razão humana permanece dividida entre as exigências da razão e as da sensibilidade, cabendo à própria razão discernir entre as suas exigências e as propostas do instinto, mantendo-se a tradicional hierarquia entre o racional e o psíquico-biológico, o puro e o empírico.

Esta distinção requer dois processos formativos, segundo Kant argumenta em Sobre $a$ pedagogia. As primeiras etapas da formação devem ser uma instrução negativa, a saber, deve-se trabalhar a disciplina, haja vista a dificuldade imposta pelas inclinações para o desenvolvimento da cultura. Menezes explicita que "As inclinações dificultam muito desenvolvimento da humanidade, porque atrapalham os homens no seu afã de estabelecer fins". (KANT, 2010, p. 110). É preciso que a vontade se liberte do despotismo dos desejos para receber da razão uma determinação que seja moralmente adequada, é preciso conceber uma boa vontade. Em um segundo momento desenvolve-se aquilo se chama instrução positiva, através da acumulação da cultura produzida pela humanidade. Kant considera que todos os homens podem passar por este processo de formação (bildung) e todos podem conformar sua vontade à moralidade, tão somente pelo fato de serem racionais, terem a priori, a capacidade de produzir uma boa vontade.

A consciência moral não é, portanto, derivada da experiência e de exemplos, pois, todos estes devem ser julgados de acordo com os princípios da moralidade. Por isso, considera Mateo, o destino do homem "en este mundo será subordinar todo lo que cae bajo El concepto de felicidad y todas las acciones que le dicta su corazón, a la fuerza orientadora del deber racional." ${ }^{8}$ (MATEO, 1981, p. 25).

\section{LEVINAS: A CARNE ÉTICA}

De origem judaica, o filósofo franco-lituano Emmanuel Levinas nasceu em Kaunas (1906) e faleceu em Paris (1995), ao eclodir a II Guerra Mundial foi capturado e feito prisioneiro pelos alemães (1939). Fortemente influenciado pela fenomenologia de Edmund Husserl (de quem foi tradutor) e pelas obras de Martin Heidegger e Franz Rosenzweig. Sua origem (judaica) e sua experiência nos campos de concentração nazista são evidentes em sua produção, quer pela escolha dos temas de reflexão filosófica, quer por sua resposta (ética) ao horror nazista.

Embora criticado por seu pendor por temas e expressões teológicos judaicos, o método fenomenológico utilizado por ele garantiria sua filiação na tradição filosófica, pelo rigor conceitual oferecido pela "ciência da essência", como é conhecida a Fenomenologia desde Husserl. Outro ponto que deve ser destacado é o fato de que para Levinas a história da Filosofia, desde sua origem, ao conferir primazia às especulações sobre o ser, esqueceu-se de algo mais fundamental e mais determinante, o encontro com a Alteridade ${ }^{9}$. Deste modo, a Filosofia constituiu uma civilização

\footnotetext{
8 "neste mundo será subordinar tudo o que está abaixo do conceito de felicidade e todas las ações que dita seu coração à força orientadora do dever racional”. (Tradução livre)

9 Sua concepção de alteridade guarda um vínculo embrionário com uma noção de "sensibilidade carnal", pois antes de emergir qualquer "sentido" em nosso encontro com o "Outro", ocorre antes o encontro face a face. Apenas, a partir deste encontro original entre os humanos é que pode emergir todo o sentido. Diante do "rosto" do outro é que o "eu"
} 
orientada para a guerra, promovida pela ideia de Totalidade, que só pode ser rompida através do encontro com infinitamente Outro.

A partir dos intérpretes da obra levinasiana, em especial Miranda (2011), encaminharemos nossas reflexões sobre o lócus da sensibilidade no fenômeno ético, reconhecendo o traço essencial que ela desempenha no aparecer ético e suas variações no conjunto da obra de Levinas, pois se em um primeiro momento a sensibilidade frui no gozo e no egoísmo do "para-si", posteriormente transforma-se o gozo em doação, "[...] esse acontecimento inscreve, na pele exposta da sensibilidade, o sentido ético da subjetividade como estrutura "um-para-o-outro", chegando à radical condição de refém e substituição "um-pelo-outro"." (MIRANDA, 2011, p. 171).

Inicialmente, em Totalidade e Infinito, a sensibilidade é descrita como fruição dos elementos do mundo, não pertencente à ordem do pensamento, da representação dos objetos, mas à ordem do sentir. Como esclarece Miranda (2011, p. 172), as qualidades sensíveis não se configuram na ordem do conhecimento mas vivem-se. Retomando exemplos contidos na obra citada, o verde das folhas, o rubro deste pôr do sol são vividos e não apenas conhecidos, em seu sentido representacional, pois os "[...] objetos contentam-me na sua finitude, sem me aparecerem num fundo de infinito. O finito como contentamento é a sensibilidade." (LEVINAS, 1980, p. 119).

Esta é a primeira relação com o mundo, como afirma Levinas (1980) “[...] fruímos do mundo antes de nos referirmos aos seus prolongamentos: respiramos, caminhamos, vemos, passeamos etc..." (p. 123). Como esclarece Miranda (2011), “[...] as qualidades sensíveis não se conhecem, vivem-se: o verde das folhas, o rubro deste pôr do sol. Os objetos contentam-me na sua finitude, sem me aparecerem num fundo de infinito. O finito como contentamento é a sensibilidade." (LEVINAS, 2000, p. 119 apud MIRANDA, 2011, p. 172).

No movimento de saída ao mundo, alimentando-se dos elementos, e voltando para-si, a sensibilidade realizaria seu ciclo de sua plena satisfação. Como fruição, a sensibilidade é assumida, afirma Miranda (2011), “[...] não como um elemento subordinado ao entendimento ou conhecimento." (2011, p. 172). Deste modo, a sensibilidade é situada na ordem do sentimento, do sentir a plenitude da fruição, por ela, "acolhemos" os elementos do mundo sem, no entanto, pensarmos neles.

Entretanto, uma tal plenitude de satisfação poderia incorrer em atitude egoísta de fechamento sobre si-mesmo, se não fosse a insegurança do amanhã que o corpo percebe que além de mergulhar no elemento, ele o habita e o possui. Citando Levinas (1980), "É na própria sensibilidade que se anuncia uma insegurança que põe em questão a antiguidade quase-eterna do elemento que a inquietará como o outro e de que ela se apropriará recolhendo-se numa morada." (p. 121) e acima da fruição esboça-se o pôr em comum - um discurso sobre o mundo. "A apropriação e a representação acrescentam um acontecimento novo à fruição. Fundam-se na linguagem como relação entre homens." (LEVINAS, 1980, p. 123).

A inscrição da linguagem que se coloca como uma representação que permite o compartilhar do elemento, inicia um novo movimento na constituição da subjetividade ética. Assim, o mundo, além de alimento torna-se uma representação do eu. Entretanto, é na irrupção

se descobre como subjetividade irrevogavelmente responsável, visando reconstruir uma subjetividade não centrada tanto no "eu", porém centrada na estrutura "um para o outro", descrita nos termos do "acolhimento e da responsabilidade". 
do rosto do outro que se inaugura uma nova relação com a alteridade. O Traumatismo do eu provocado pela epifania do rosto do outro é o que inscreve um sentido ético na sensibilidade, como acolhimento e responsabilidade ao outro (um-para-o-outro). O Próximo é compreendido como o Outro, que surge como rosto, cujo significado antecede à representação. Deste modo, o rosto é compreendido como significância ética, surgindo como o elemento novo capaz de produzir um traumatismo no eu e inscrevendo no bojo da sensibilidade o acolhimento e a responsabilidade ao outro o sentido ético da subjetividade.

A sensibilidade como "contato" e "proximidade" com o Outro, é a sensibilidade concebida nos termos de "acontecimento de proximidade". Para Levinas o próximo não segue "a medida e o ritmo da consciência" (LEVINAS, 1998, p. 280); não é definido a partir de uma categoria conceitual, na qual sua alteridade é desde já neutralizada, pois o "Próximo é precisamente aquilo que tem o sentido imediatamente, antes de lhe conferirmos. Mas aquilo que tem, assim, um sentido só é possível como Outrem, como aquele que tem um sentido antes de the atribuirmos". (LEVINAS, 1998, p. 279) A essa auto-significância por excelência do próximo, Levinas denomina de "rosto". Sendo que tal proximidade não se realizaria através da consciência intencional, pois deste modo o rosto do Outro se prestaria à tematização epistemológica e esvaziamento ético.

Para o filósofo franco-lituano, aproximar-se do Outro significa sentir, tocar, entrar em contato com o próximo, situa-se além da mediação conceitual e dos dados apreendidos à distância no conhecimento (MIRANDA, 2011). Consiste, nos termos definidos por Levinas (1998, p. 287) “[...] em aproximar-se de Outrem, mantendo uma relação não alérgica à sua irredutível alteridade [...] esta transformação do dado em próximo e da representação em contato, o saber em ética, é rosto e pele humana". É a partir da relação de proximidade entre o Eu e o Outro que o discurso é Inaugurado, pois "seja qual for a mensagem transmitida pelo discurso, o falar é contato" (LEVINAS, 1998, p. 274).

Trata-se de uma compreensão ética que promove uma inversão da relação entre a subjetividade e a alteridade, pois a subjetividade ao entrar em contato com a singularidade do Outro, anula sua identificação do Outro com um ideal, não tematiza a alteridade como uma representação, mas encontra-se face a face com uma singularidade absoluta e como tal irrepresentável. Para Levinas, aí está a linguagem original, fundamento do Outro.

No contato com o próximo instala-se uma inquietude que se produz como um traumatismo no contato com a proximidade do próximo, sentida pelo humano na pele exposta da sensibilidade, e não pensada abstratamente por meio da razão. Assim, o terceiro momento da sensibilidade no fenômeno ético surge em Levinas em sua obra De otro modo que ser o más allá de la esencia (1974), em que ela (sensibilidade) é pensada em termos de fruição (gozo) e de ferida (sofrimento) na relação de proximidade, vindo a constituir uma subjetividade caracterizada como vulnerabilidade, em outros termos, "[...] como passividade de uma subjetividade exposta desde a sua própria pele aos prazeres e ultrajes do mundo." (MIRANDA, 2011, p. 177).

No contexto desta obra, Levinas reafirma sua concepção de que não é a ontologia a prima ciência, mas é a Ética que deveria ter primazia na constituição da tradição filosófica. Deste modo, pensar o sentido do humano para além das categorias ontológicas do ser e não-ser significa a abertura de um caminho fecundo para se pensar a subjetividade para além da essência do ser. Assim, como esclarece Miranda (2011) "nessa perspectiva de saída do ser, entendido como referência última, a humanidade e a subjetividade aparecem como a possibilidade de explosão 
desta alternativa, pois significam 'um-no-lugar-do-outro', o que consiste no dizer da própria "substituição"" (p. 177).

A subjetividade, estruturada por tais elementos é descrita na forma de completa passividade que exposta à Alteridade expressa a vulnerabilidade da sensibilidade, em um sentido de doação do próprio pão que se come como conversão do gozo em resposta ética face o rosto do Outro. Mas como alerta Levinas (2003), para que o sentido ético da doação aconteça, "é necessário previamente gozar de seu próprio pão, não a fim de ter o mérito de dá-lo, senão para dar com ele o seu coração, para dar-se no ato de dá-lo. O gozo é um momento inevitável da sensibilidade" (MIRANDA, 2011, p. 178).

Em suma, a sensibilidade para Levinas é fruição (gozo) contato (proximidade), vulnerabilidade (exposição, ferida, sofrimento), diferentes termos que configuram a complexa descrição fenomenológica da subjetividade. Trata-se de uma concepção de sensibilidade sem a qual não haveria fenômeno ético, constituindo-se em elemento de base da própria subjetividade, que inscrita no seio da intriga ética entretece a relação face-a-face com o Outro.

\section{CONCLUSÃO}

A formulação ética kantiana impõe ao homem uma tarefa: esclarecer-se a si mesmo, ter coragem para fazer uso de seu entendimento, alcançar a maioridade e pensar por si mesmo. A vontade e a sensibilidade não podem conduzi-lo a esta vida autônoma, haja vista que são do domínio da dependência externa, pathós. Contudo, talvez seja apressado afirmar que a proposta kantiana despreze a dimensão afetiva e instintiva do homem. O filósofo admite que a finalidade da sensibilidade seja a felicidade, donde decorre o sumo bem, alcançado como realização máxima da vida feliz, pois, neste caso há uma dupla realização, pela concordância da razão com o desejo e a sensibilidade, ainda que esta apareça de modo secundário frente a razão, livre de determinações empíricas.

Já na perspectiva levinasiana, o sensível somente pode ser visto como superficial quando subordinado ao conhecimento, pois, entendido na perspectiva da relação ética, na sua relação de contato e proximidade, o sensível cumpre sua função essencial. É nessa relação de contato e proximidade com o outro, que o sensível é visto como elemento capaz de tecer uma nova relação ética com o próximo.

A subjetividade encontra, na sensibilidade, a via primordial de relação com o Outro, via construída não a partir da representação do mundo, mas a partir do contato e da proximidade. Subjetividade que é sempre resposta, substrato que, na sua passividade, responde como responsabilidade pelo Outro, entretecida na sensibilidade como vulnerabilidade da subjetividade, ao mesmo tempo como fruição e sofrimento e não como representação e pensamento.

Embora circunscrito à hermenêutica de textos filosóficos, necessária ao esclarecimento conceitual e produção de sentido, passo necessário à pesquisa em Educação, a presente investigação desdobrar-se-á nos efeitos de tais teorias sobre o campo educativo, em especial nas questões da didática e da relação professor-aluno. 


\section{REFERÊNCIAS BIBLIOGRÁFICAS}

1. ANDRADE, R.C.L. Formação Moral e Educação: um estudo a partir da filosofia prática de Kant. Marília, 2013. Tese de doutorado. Universidade Estadual Paulista, 2013.

2. CARVALHO, A. B. Razão e Paixão: Necessidade e contingência na construção da vida ética. Conjectura, v. 17, n. 1, p. 199-217, jan./abr. 2012.

3. GADAMER, H.-G. O problema da consciência histórica. Trad.: Paulo Cesar Duque Estrada. Fundação Getúlio Vargas Ed.: Rio de Janeiro, 1996.

4. KANT, Immanuel. Crítica da Razão Pura. Trad. e notas de Fernando Costa Mattos. Petrópolis, RJ: Vozes; Bragança Paulista, SP: Editora Universitária São Francisco, 2012a.

5. Resposta à pergunta: Que é esclarecimento? (Auflkarung) Trad. Floriano de Souza Fernandes. In: KANT, I. Textos Seletos. 8a edição. Petrópolis, RJ: Vozes, 2012b, p. 63-71.

6. Começo conjctural da história humana. Trad. Edmilson Menezes. São Paulo, SP: Editora Unesp, 2010.

7. LEVINAS. E. Totalidade e Infinito. Trad. José Pinto Ribeiro. Lisboa: Ediçoes 70, 1980.

8. Linguagem e Proximidade. In: Descobrindo a existência com Husserl e Heidegger. Lisboa: Inst. Piaget, 1998.

9. MATEO, M.S. Razón y sensibilidad em la ética de Kant. Tucuman (Argentina): 1981.

10. MIRANDA, J.V.A. A sensibilidade ética em Emmanuel Levinas. Kínesis, Vol. III, $n^{\circ}$ 06, p. 170183, Dez. 2011.

11. PEREIRA, J.A. Crítica de Levinas ao sujeito moral de Kant. Polymatheia, Vol. IV, no 5, p.99-111, 2009. 